\title{
O QUE TOCA À/A PSICOLOGIA ESCOLAR: DESDOBRAMENTOS DO ENCONTRO ENTRE PSICANÁLISE E EDUCAÇÃO
}

\section{Maria Cristina Machado Kupfer}

Em 1997, o artigo "O que toca a/à Psicologia Escolar" foi escrito com a intenção de traçar e sistematizar algumas balizas para o trabalho do psicólogo escolar que escolheu orientar-se pela psicanálise.

À época, buscar uma prática institucional, em qualquer que fosse a instituição - escola ou hospital - orientada pela psicanálise não era óbvio. Não era de fácil proposição uma prática psicanalítica fora das quatro paredes de um consultório. Assim, muito do que se escreveu naquele artigo tinha sabor de heterodoxia.

Passados vinte anos, pode-se indagar: o que sobreviveu das ideias ali traçadas? Levar a psicanálise à educação é ainda hoje uma heterodoxia?

Naquele texto, a intenção era definir a posição do profissional dentro da escola, sua direção de trabalho e os parâmetros que poderiam orientá-lo, tomando como base a teoria e a clínica psicanalíticas, já que um dos eixos da discussão era a noção de transferência.

Resumindo cada uma das direções ali apontadas, o artigo afirmava que um psicólogo não atende, nem recusa as demandas que uma escola dirige a ele: ele as escuta. A escuta é um instrumento de trabalho propício à emergência de falas de sujeitos que quebram a repetição dos discursos institucionais e auxilia no relançamento da circulação da fala. Para isso, organiza espaços de trabalho: grupos de professores e de crianças. Essa escuta só poderia ser efetiva se estivesse apoiada na transferência do professor e da escola com o profissional psicólogo orientado pela psicanálise.

Havia ainda a noção de espaço psi. O espaço psi foi apresentado como um espaço construído pela presença de um psicólogo na escola. Em sua definição, não coincide com o espaço físico de uma sala de atendimento. Ele se espalha por toda a escola e se desenha a partir das múltiplas relações que se constroem em todos os cantos da escola: do psicólogo com os alunos, com os professores e com o pessoal administrativo.

artigo baseou-se também no princípio segundo o qual toda instituição - inclusive a escola - está estruturada como uma linguagem e segue, assim, os princípios de seu funcionamento. Chamava a atenção para o fato de que uma instituição é feita de discursos, que tendem a produzir repetições, mesmices, na tentativa de preservar o estabelecido e garantir sua permanência.

Por que seria necessário interromper a repetição? Porque, havendo apenas discursos cristalizados, cessariam a "oxigenação" da instituição e os efeitos de transformação que surgem quando há espaço para emergências ou falas singulares. E, se as falas singulares não 
emergem, não há nova circulação discursiva. Sem renovação, uma instituição só poderá recuar e morrer.

A mudança adviria, então, quando emergissem falas de sujeitos, responsáveis pela produção de "rachaduras" naquelas repetições. A conclusão do texto foi que um psicólogo poderia operar como "auxiliar de produção" de tais emergências.

Havia também uma discussão de pano de fundo: como trabalhar a dimensão psíquica e levar em conta ao mesmo tempo os determinantes sociais que incidem sobre a escola? A resposta dada era que se devia operar com uma distinção entre eu e sujeito. $\bigcirc$ primeiro pode ser pensado como um precipitado de identificações e aberto aos determinantes sociais, ao passo que a psicanálise se ocupa do sujeito.

Com algumas metáforas musicais, o artigo sugeria que a escola poderia ser comparada a um coro, cabendo ao psicólogo o lugar de quem está na plateia, ouvindo a música desafinada ou melodiosa - que a escola estivesse entoando.

Os operadores principais do artigo eram as noções de escuta, de transferência e de discurso, tendo como fundo a discussão sobre os determinantes sociais das dificuldades psicológicas vividas nas escolas pelos professores ou alunos.

Um exame do percurso percorrido no campo das articulações da psicanálise com a educação poderá ser útil para responder à pergunta sobre como estamos hoje em relação aos pontos levantados no esboço de 1997.

\section{A PRODUÇÃO BRASILEIRA NO CAMPO DAS ARTICULAÇÕES PSICANÁLISE E EDUCAÇÃO}

Dois artigos, o primeiro publicado em 2010 e o segundo em 20 I 5, na revista Estilos da Clínica - Revista sobre a Infância com Problemas, buscaram fazer esse balanço.

O primeiro artigo (Kupfer et al., 20।0) fez um levantamento da produção brasileira no campo das articulações entre psicanálise e educação de 1989, quando os pesquisadores do Laboratório de Estudos e Pesquisas Psicanalíticas e Educacionais sobre a Infância (LEPSI/IP-FEUSP) iniciaram as discussões das grandes balizas no campo das articulações da psicanálise com a educação, a 20 I0. Esse levantamento demonstra uma expansão significativa desse campo, sobretudo nos últimos vinte anos: foram registrados 277 trabalhos em todo o país entre 1986 e 2010.

No Brasil, houve um ressurgimento desses estudos na década de 1980, com autores como Mokrejs (1986) e Lopes (2003). A publicação de Freud e a educação (Kupfer, 1989) chama a atenção dos educadores de forma paradoxal. $\bigcirc$ livro seguia de perto as considerações de Millot (1967/1987) sobre a inaplicabilidade da psicanálise à educação, mas provocou o interesse dos educadores pelo fenômeno da transferência, tema também presente no artigo de 1997 que está sendo aqui examinado. Para o educador, conhecer a noção de transferência produzia uma ilusão de domínio sobre ela, marcada pela demanda crescente pelo saber psicanalítico e dos cursos que o transmitiam.

O levantamento realizado em 2010 localizou algumas direções de trabalho em que se propunham articulações entre a psicanálise e a educação. As direções ou temas apontados pelo levantamento eram, predominantemente: a) a transferência no campo educativo; 
b) as relações entre Psicanálise, discurso pedagógico e educação na contemporaneidade; c) alunos e professores na relação com o saber; d) as relações entre tratar e educar; e) a formação de professores a partir da psicanálise.

Além dos temas predominantes, foram localizadas duas posições teóricas diante da articulação entre psicanálise e educação.

$\mathrm{Na}$ literatura levantada, foram encontradas maneiras diversas de encarar essa articulação. Havia textos que faziam apenas uma justaposição entre os dois campos. Colocavam-nos de forma paralela e faziam considerações sobre eles, sem extrair consequências ou fazer cruzamentos conceituais. Havia também textos marcados por uma orientação ideológica e prescritiva, em que a psicanálise ditava o que deve ser realizado no campo da educação. Havia ainda os que designavam a tarefa de iluminar processos subjacentes ao campo educativo para a psicanálise. Em todos eles, apresentava-se uma relação de exterioridade de um campo em relação ao outro.

A abordagem adotada pelo LEPSI e exposta no levantamento de 2010 não é nenhuma das mencionadas até aqui. Para aquele grupo, trata-se de "supor a criança-sujeito como um só, e de ampliar o ato educativo de modo a incluir sua dimensão libidinal, constitutiva e implicada na construção do sujeito do desejo, ato que se dá ao mesmo tempo em que se dá o ato pedagógico"' (Kupfer et al., 2010, p.289-290).

Outro campo de ação para o psicólogo orientado pela psicanálise ganhou destaque e cresceu nos últimos vinte anos, tendo sido levantado no artigo de 2010 . Essa perspectiva de trabalho, chamada de Tratar e educar, desenvolveu-se como uma tentativa de pensar um procedimento de tratamento dirigido às crianças psicóticas e autistas que estivesse articulado à escolarização. Surgiu, naquele período, a Educação Terapêutica.

A Educação Terapêutica foi definida como um conjunto de práticas interdisciplinares de tratamento, com ênfase nas práticas educacionais, que visa à retomada do desenvolvimento global da criança e da estruturação do sujeito do inconsciente e a sustentação do mínimo de sujeito que uma criança possa ter construído. Na base da construção da Educação Terapêutica está o pressuposto de que as práticas analíticas e educacionais com crianças psicóticas caminham na mesma direção, diferentemente do que ocorre quando se trata de crianças neuróticas. Quando estamos diante da psicose e do autismo, o tratamento e a educação podem convergir.

Educar essa criança na escola seguirá os mesmos princípios de seu tratamento. Mais que isso: no campo da Educação Terapêutica, tratar e educar estão mais próximos do que no campo da educação regular. Colocá-la na escola fará parte de seu tratamento. Educar será tratar, e tratar será educar.

Essa perspectiva de trabalho articula-se ao crescimento da ação do psicólogo em relação às práticas inclusivas, que ganharam corpo a partir da década de 1990, impulsionadas pelas diretrizes propostas pela Declaração de Salamanca em 1994.

Em 2015, novo estado da arte foi proposto por Pereira e colaboradores para o período 1987-2012 (Pereira e Silveira, 2015). Naquele levantamento, ou survey, para usar o termo americano, a busca foi mais abrangente, e por isso foram registrados 635 trabalhos que mostram o quanto o campo cresceu em números absolutos. Esses 
trabalhos foram distribuídos em treze eixos temáticos: I. Subjetividade ( 1 I 3 títulos); 2. Psicanálise e educação (92); 3. Infância (80); 4. Relação professor-aluno (74); 5. Formação de professores (65); 6. Aprendizagem (60); 7. Inclusão (60); 8. Mal-estar docente (58); 9. Adolescência (54); 10. Saúde mental, autismo, TDAH (37); I I. Violência (28); 12. Linguagem (24); 13. Fracasso escolar (20).

Quase $40 \%$ dos trabalhos concentram-se em eixos temáticos em torno da subjetividade e de teorias da psicanálise e educação. Os professores são alvo privilegiado dos trabalhos encontrados: se reunirmos os temas "mal-estar docente", "relação professor-aluno" e "formação de professores", encontraremos 197 trabalhos, ou um terço da produção total.

que foi especialmente tratado em relação ao trabalho com professores? Esse professor foi encarado de forma preponderante como sujeito do inconsciente, ainda que focalizado em seu trabalho como educador. Em seguida, ao dedicar-se especialmente ao estudo da relação do professor com seu aluno, os trabalhos deram ênfase, majoritariamente, à noção de transferência aplicada ao âmbito educacional, buscando o entendimento de como ela pode ser identificada e manejada na relação professor-aluno. São, porém, trabalhos preocupados em pensar o apropriado de trazer a transferência para âmbitos não analíticos. Um dos trabalhos propôs investigar "se esta especificidade [transferência] exige um educador diferenciado ou um 'analista especialista"' (Gutierra, 2002, citado em Pereira e Silveira, 2015).

O tema Inclusão Escolar foi contemplado em 60 trabalhos, ou cerca de 10\% da produção do campo. Somado ao tema saúde mental e autismo (37), foram I5\% do total.

A questão dos determinantes sociais aparece de forma rápida nos trabalhos que discutem o fracasso escolar. São trabalhos que "enfatizam as determinações sociais, quando buscam responder às causas do fracasso escolar a partir da influência das condições do meio em que os sujeitos estão inseridos. [...] Outros estudos tratam de maneira mais isolada temas que giram em torno da tensão entre a educação formal e a informal, o que faz acirrar o conflito entre as práticas escolares e as normas familiares. Há ainda estudos que consideraram o fracasso escolar como sintoma social" (Pereira et al, 20 l5). Assim, a tensão entre o social e o psicológico continuou surgindo, mas de modo pouco significativo.

\section{VOLTANDO AO ARTIGO DE 1997}

Para a discussão que se pretende fazer neste artigo, pode-se observar nos surveys citados que os esforços de prosseguir fazendo aproximações entre a psicanálise e o campo educativo não morreram e deixaram de ser heterodoxia. Além disso, o campo das articulações entre psicanálise e educação conheceu uma expansão significativa.

tema da transferência prosseguiu sendo focalizado pelos trabalhos seguintes, com ênfase no estudo da figura do professor e pensando, sobretudo, em suas relações com os alunos. Mas são poucos os trabalhos que se preocuparam em pensar transferencialmente as relações entre professores e profissionais que vão à escola para trabalhar as relações institucionais - caso do psicólogo escolar - como no artigo de 1997. Encontram-se ali os 
trabalhos que "investigam as possibilidades da devolução ou oferta da palavra ao professor através da escuta ou da escuta ampliada de seus sofrimentos psíquicos". Um dos títulos conclui que "na medida em que o professor fala acerca do mal-estar, sua própria fala conduz sua ação em outra direção, tomando para si a responsabilidade por seus atos educativos" (Schonardie, 2000, citado em Pereira et al., 2012). A escuta do professor e de seu mal-estar cresceu de modo importante. Destacam-se os trabalhos de Aguiar e Almeida (2008) e de Pereira (2016), mas o foco não está mais na relação transferencial entre psicólogo e professor.

Assim, a escuta e a leitura da transferência prosseguem sendo o alvo do psicólogo escolar que vai à escola orientado pela psicanálise, embora se trate de um foco menos desenvolvido em relação aos outros temas analisados.

Os discursos, esses sim, tiveram amplo desenvolvimento. Sob a rubrica Psicanálise e Contemporaneidade, apontada no primeiro levantamento, estão os estudos que se valem da elaboração lacaniana dos quatro discursos. Embora não abordada nos dois levantamentos, a leitura dos discursos com ênfase na leitura das escolas é amplamente utilizada. Pode-se mencionar os trabalhos de Lerner (20 I3), Bastos (20I2) e Voltolini (20II). Assim, o que foi afirmado no artigo de 1997 conserva atualidade e poderá ser útil aos profissionais que se dispuserem a escutar professores nas escolas.

O tema "Tratar e Educar" também expandiu significativamente. Mostra-se ainda presente o trabalho do psicanalista ou do psicólogo no âmbito do tratar e educar, a exemplo do que apontou o primeiro levantamento.

Trata-se de uma discussão que ganha contornos mais nítidos em nosso momento. Se não apareceu com clareza nos levantamentos assinalados, conheceu um aumento significativo nos últimos cinco anos. É nítida a entrada do psicólogo nas escolas para discutir práticas inclusivas e significativa a sua colaboração para agregar a essas discussões a noção de que há um sujeito no aluno em situação de inclusão, um aluno que precisa ser acolhido e escutado a partir de uma perspectiva psicanalítica.

Quanto aos determinantes sociais, é um tema que pode ser retomado em outros termos. Como deve ser encarada a determinação histórico-política dos movimentos institucionais em uma escola? É o sujeito agente de sua própria história ou está sujeitado às forças inconscientes que o determinam e Ihe tiram a liberdade? A resposta de Peters (2000) permite avançar na discussão colocada em 1997: o sujeito é "dependente do sistema linguístico; é um sujeito discursivamente constituído e posicionado na intersecção entre as forças libidinais e as práticas socioculturais". Trata-se de uma resposta que coincide com a da psicanálise, segundo a qual o sujeito é primeiramente e sempre sujeitado ao Outro, limitado pela castração, o que não o torna livre.

Essa concepção, porém, não impede a psicanálise de supor que um sujeito, educado para dizer-se e estar próximo de sua verdade, se torne um agente de transformação, um homem que recusará qualquer coerção escusa exercida sobre ele que o impeça de manifestar seu desejo e sua verdade com os instrumentos da cultura. Dessa perspectiva, é possível que um psicólogo orientado pela psicanálise introduza em uma escola uma prática em que são levados em conta o sujeito do inconsciente e o sujeito agente que produz sua própria história. 


\section{O PSICANALISTA/PSICÓLOGO NAS CRECHES}

Mas será que nada mais se desenvolveu a partir da ideia de um profissional que trabalhe na escola com parâmetros da psicanálise? Se esses parâmetros não são mais exatamente os do espaço psi, quais parâmetros foram criados nos últimos vinte anos e que poderiam passar a vigorar dentro daquele mesmo espírito?

Os IRDls - Indicadores Clínicos de Risco -, construídos a partir da psicanálise, podem ser atualmente considerados como novos parâmetros do espaço psi no âmbito escolar. Criados originalmente para serem utilizados por pediatras em consultas regulares, o instrumento foi adaptado para uso no campo educativo. Como se aplicam apenas a crianças de zero a dezoito meses, o âmbito educativo em que podem ser úteis como parâmetros de trabalho para o psicólogo é o das creches.

A metodologia IRDI define-se como um procedimento de acompanhamento da constituição subjetiva feito por psicanalistas em instituições de educação infantil por meio de indicadores clínicos com valor de previsão precoce de problemas de desenvolvimento ulteriores (Kupfer, Bernardino e Mariotto, 20।4).

A pesquisa nas creches passou a ser chamada de Metodologia IRDI nas creches e obteve resultados extremamente favoráveis: mostrou que o acompanhamento do par professor-bebê aumenta a chance de o bebê mostrar um desenvolvimento livre de entraves subjetivos a partir do terceiro ano de vida.

Na metodologia IRDI nas creches, o professor e seu bebê são lidos a partir de indicadores, que são referências de leitura, parâmetros que organizam o olhar do profissional e buscam favorecer o professor - a partir da transferência e na escuta - a se reposicionar e se tornar um agente auxiliar da subjetivação dos bebês nas creches.

$\bigcirc$ apoio ao professor baseou-se na ideia de que se deve fazer um holding do holding (Boukobza, 2007). Aquele que cuida - o professor na creche - precisa também receber cuidados, apoio e sustentação. Essa era a ideia do espaço psi: construído na transferência e com a escuta, a partir do qual o professor que ensina ou cuida é escutado para ser apoiado e colocar em constante circulação os discursos ensinantes ou subjetivantes.

Assim, as ideias de 1997 não morreram. Desdobraram-se e encontraram novos caminhos. A música continua! 


\section{REFERÊNCIAS BIBLIOGRÁFICAS}

Aguiar, R. M. R, \& Almeida, S. F. C. (2008). Mal-estar na educação: o sofrimento psíquico de professores. Curitiba: Editora Juruá.

Bastos, M. B. \& Kupfer, M. C. M. (20 I0). A escuta de professores no trabalho de inclusão escolar de crianças psicóticas e autistas. Estilos da Clínica, v. I 5 (I), p. I I 6- 125.

Boukobza, C. (Org.) (2007). Les écueils de la relation précoce mère-bébé. Ramonville SaintAgne, França: Érès.

Declaração de Salamanca sobre Princípios, Política e Prática em Educação Especial. (1994). Salamanca: S.I..Recuperado de http/mec.gov.br.

Kupfer, M. C. M. ( 1989). Freud e a educação: o mestre do impossível. São Paulo: Scipione.

Kupfer, M.C. et al. (20 I0). A produção brasileira no campo das articulações entre psicanálise e educação a partir de 1980. Estilos da Clínica, I5(2), 284-305.

Kupfer, M. C., Bernardino, L. M. F., \& Mariotto, R. M. M.(Org) (20|4). De bebê a sujeito: a metodologia IRDI nas creches. São Paulo: Escuta/FAPESP, 304 p.

Lerner, A. B. C. (2013). Consequências éticas da leitura psicanalítica dos quatro discursos para a educação inclusiva. Tese de doutorado. Faculdade de Educação, Universidade de São Paulo, São Paulo, SP, Brasil.

Lopes, E. M. T. (2003). Da sagrada missão pedagógica. Bragança Paulista: Editora Universitária São Francisco (trabalho original publicado em 199|).

Millot, C. ( 1987). Freud antipedagogo. Rio de Janeiro: Jorge Zahar Editor. (trabalho original publicado em 1967).

Mokrejs, E. (1986). Divulgação das primeiras ideias psicanalíticas no Brasil. Tese de Doutorado. Faculdade de Educação, Universidade de São Paulo, São Paulo, SP, Brasil.

Pereira e Silveira. (2015). Análise do estado da arte em psicanálise e educação no Brasil (1987- 20 I2). Estilos clin., São Paulo, (20) 3, set./dez., 369-390.

Pereira, M. R. (20 I 6). O nome atual do mal-estar docente ( I ${ }^{\mathrm{a}}$ ed.). Belo Horizonte: FinoTraço/ Fapemig.

Peters, M. (2000) Pós-estruturalismo e filosofia da diferença. Belo Horizonte: Autêntica.

Voltolini, R. (20 I I). Educação e Psicanálise ( I ${ }^{\mathrm{a}}$ ed.). Rio de Janeiro: Zahar. 
